ГORIGINAL ARTICLE

Volume 16 Issue 12021

DOI: 10.21315/aos2021.16.1.6

ARTICLE INFO

Submitted: $24 / 2 / 2021$

Accepted: 21/4/2021

Online: $25 / 6 / 2021$

\section{Fluoride and Functionalised $\beta$-tricalcium Phosphate (fTCP) Fluoride Toothpaste Affect the Primary Dentin Caries Surface: A Comparison by Estimation Statistics}

\author{
Trieu Kim Ly, Thoai Quoc Kieu, Nam Cong-Nhat Huynh*, \\ Lan Thi Quynh Ngo \\ Department of Dental Basic Sciences, Faculty of Odonto-Stomatology, \\ University of Medicine and Pharmacy at Ho Chi Minh City, 652 Nguyen \\ Trai, Ward 11, District 5, Ho Chi Minh City 749000, Vietnam \\ ^Corresponding author: namhuynh@ump.edu.vn
}

How to cite this article: Ly TK, Kieu TQ, Huynh NCN, Ngo LTQ (2021). Fluoride and functionalized $\beta$-tricalcium phosphate (fTCP) fluoride toothpaste affect the primary dentin caries surface: A comparison by estimation statistics. Arch Orofac Sci, 16(1): 57-67. https://doi.org/10.21315/ $\operatorname{aos} 2021.16 .1 .6$

To link to this article: https://doi.org/10.21315/aos2021.16.1.6

\begin{abstract}
This study aims to compare the effect of fTCP-contained toothpaste in combination with 950 ppm fluoride on primary dentin caries surface to ordinary $1100 \mathrm{ppm}$ fluoride toothpaste by using estimation statistics. Dental caries with deep lesion and dentin exposure from nine primary teeth were cut into two equal parts and randomly divided into two groups in a before-after study. Each group was brushed with one type of toothpaste two times per day for 28 days and rested in artificial saliva. SEM images of cavity bottom surfaces and energy-dispersive X-ray spectrometry (EDX) were used to determine the percentage of calcium $(\mathrm{Ca})$, phosphorus $(\mathrm{P})$, fluoride $(\mathrm{F})$ and oxygen $(\mathrm{O})$ at six continuous measured areas from the surface of the cavity bottom into $45 \mu \mathrm{m}$ depth before and after brushing. About $95 \%$ confidence interval of the mean difference was calculated by performing bootstrap resampling with 5000 resamples followed by comparison analysis. The percentage of $\mathrm{Ca}, \mathrm{P}, \mathrm{F}, \mathrm{O}$ was shifted after treatment. There was no difference between the two groups. The SEM images reflected a similar illustration of EDX data. The combination of fTCP and $950 \mathrm{ppm}$ fluoride in toothpaste showed equivalent effectiveness to the 1100 ppm fluoride toothpaste in primary dentin caries.
\end{abstract}

Keywords: Fluoride; fTCP toothpaste; primary dentin caries; remineralization

\section{INTRODUCTION}

Early childhood caries (ECC) is a serious public health challenge in both developing and developed countries. In Southeast Asia countries, recent studies reported a much higher prevalence of ECC than those in developed countries due to the high-frequency sugar intake, inappropriate sweetened feeding bottles, the lack of oral hygiene and low socioeconomic status (Karlinsey et al., 2009; Khanh et al., 2015). ECC progresses rapidly and often be untreated, affecting not only the general health but also the life quality of children. As a chronic infectious disease, bacteria, mainly Streptococcus mutans and Streptococcus sobrinus, cause a tooth decay lesion by acids from bacterial metabolism, changing from local environmental conditions to 
an acidic environment and resulting in demineralisation of dental hard tissues. Remineralisation, on the other hand, is a natural repair process occurring on the non-cavitated carious lesions. It rebuilds a new surface containing remineralised crystals which are acid-resistant. Therefore, increasing remineralization is key to ECC management and prevention (Sumikawa et al., 1999).

The most effective method to prevent tooth demineralization and enhance the remineralization is topical fluoride application therapy, such as toothpaste and varnish (ten Cate, 2013). Fluoride ions speed up the remineralisation process, together with calcium and phosphate ions, diffuse into the tooth and form fluorapatite, which is much less soluble than carbonated hydroxyapatite and more difficult to dissolve by organic acids from bacterial metabolism. However, to form one unit of fluorapatite $\left[\mathrm{Ca}_{10}\left(\mathrm{PO}_{4}\right)_{6} \mathrm{~F}_{2}\right]$, every two fluoride ions require ten calcium ions and six phosphate ions. Therefore, even the existence of an appropriate amount of fluoride ions, the remineralisation process can be restricted by the inadequate availability of calcium and phosphate ions. Functionalized $\beta$-tricalcium phosphate (fTCP) and fluoride-containing toothpaste have been developed for this reason (Karlinsey \& Pfarrer, 2012). fTCP works in synergy with fluoride to form a more acid-resistant mineral incorporation to that attainable with fluoride or fTCP alone by the encouragement of greater calcium, phosphate, and fluoride uptake in demineralised areas, thus preventing demineralisation and enhancing remineralisation. Recently, numerous studies have demonstrated anticarcinogenic activity and remineralisation effect of $\mathrm{fTCP} /$ fluoride (F-fTCP) toothpaste. However, most studies were in vitro experiments on artificial caries like enamel lesions (demineralized by acidic solutions such as $\mathrm{Ca}\left(\mathrm{Ca}\left(\mathrm{NO}_{3}\right)_{2}\right.$, $\mathrm{PO}_{4}\left(\mathrm{KH}_{2} \mathrm{PO}_{4}\right)$ and acetate) or in situ experiments using bovine root dentin blocks (Oliveira et al., 2016; Kamath et al., 2017; Alhamed et al., 2020).
Following up on those insights, our study for the first time evaluated the effects of fluoridated (NaF, $1100 \mathrm{ppm} \mathrm{F}$ ) and fTCP/ fluoride-containing toothpaste $(950 \mathrm{ppm} \mathrm{F}$ ) on primary dentin caries surface by using energy-dispersive X-ray spectroscopy (EDX) and scanning electron microscope (SEM). In this study, we applied estimation statistics for the comparison analysis. The limitations of null-hypothesis significance testing have been discussed while the use of $P$ values can lead to biased analyses because false positives may be overhyped, and some real effects are ignored. Estimation methods that estimate effect sizes and their uncertainty have great potential to shift the current data analysis away from dichotomous thinking and toward quantitative reasoning (Efron, 1992; Amrhein et al., 2019; Wasserstein et al., 2019). This study could add new evidence to the effect of $\mathrm{fTCP} /$ fluoride-containing toothpaste and fluoride toothpaste.

\section{MATERIALS AND METHODS}

\section{Specimen Preparation}

Nine primary teeth extracted because of their mobility and time for exfoliation from nine patients from 6 to 12 -year-old at the Dental Treatment Center of the University of Medicine and Pharmacy at Ho Chi Minh City were used as specimens in a beforeafter study. The teeth exhibited dentin caries involving the dentin of the buccal surface with a caries lesion size larger than $2 \times 2 \mathrm{~mm}$ without hypoplastic areas. The teeth were cleaned to remove calculus and remaining soft tissue. The specimens were then stored in distilled water until use. The use of discarded tissues for research purposes was approved by the Ethics Committee of the University of Medicine and Pharmacy at Ho Chi Minh City as a required part of graduate study (Ref. No.: 8720501).

The teeth were de-identified and analysed anonymously. Caries lesion in buccal surfaces was perpendicularly separated into two blocks using a water-cooled diamond- 
impregnated low-speed saw (Fig. 1A). Two blocks of the sample were obtained from each tooth. The cutting edge of the specimens was then polished using a $1 \mu \mathrm{m}$ diamond polishing suspension with a polishing cloth. To prevent unexpected contact with the demineralising and remineralising agents, the enamel surfaces were painted with acid-resistant varnish, except for a window of $2 \times 1 \mathrm{~mm}$ of caries lesion.

\section{Experimental Design}

Eighteen blocks of the sample were randomly and equally divided into two groups: group $\mathrm{F}$ - Colgate ${ }^{\circledR}$ Total Clean Mint (1100 ppm F as NaF; Colgate-Palmolive, New York, NY, USA) and group $\mathrm{T}$ (F-fTCP) - Clinpro ${ }^{\mathrm{TM}}$ Tooth Crème (fTCP $+950 \mathrm{ppm} F$ as NaF; 3M, St Paul, MN, USA) (Fig. 1B). A standardised volume $(0.15 \mathrm{~mL})$ of the agent was applied to each sample for two minutes, twice a day for 28 days by orthodontics toothbrushes using brushing action. The specimens were rinsed with $10 \mathrm{~mL}$ distilled water and then soaked in the artificial saliva $(\mathrm{pH}=7.1)$ solution in a $37^{\circ} \mathrm{C}$ incubator (Yamaguchi et al., 2006). The artificial saliva solution was changed daily.

\section{SEM and EDX Analysis}

To evaluate and compare the remineralisation effect of each kind of toothpaste, SEM and EDX measurements of individual specimens were recorded and analysed before and after treatments. For SEM analysis, the specimens were dehydrated in increasing grades of ethanol $(30 \%, 50 \%, 70 \%, 90 \%, 96 \%$ and $100 \%)$ for 10 minutes each grade and then freezedried at $-30^{\circ} \mathrm{C}$ in a vacuum desiccator (de Azevedo et al., 2014). The dried specimens were then mounted on to a SEM stub without coating. After that, tooth surfaces were analysed under a SEM-EDX spectroscopy (JSM - IT100, JEOL, Tokyo, Japan) at $\times 30, \times 250, \times 1000$ and $\times 2000$ magnifications using biological sample measurement setting. SEM photomicrographs were captured at $1000 \times$ magnification $(20 \mathrm{kV}$ voltage, low vacuum-45 $\mathrm{Pa}$ ).

Following the SEM examination, EDX analysis was performed with the same SEMEDX spectroscopy to determine weight percentages of calcium (Ca), phosphorus $(\mathrm{P})$, oxygen $(\mathrm{O})$ and fluoride $(\mathrm{F})$ content of each specimen. The representative measurement areas were selected under $1000 \times$ magnification. The chemical elements analysis was performed on the surface of the cross-sections, starting at the outer layer of tooth surface moving pulp-wards (Fig. 2A). In total, five measurements (at $0-5,5-10$, $10-15,15-20,20-25 \mu \mathrm{m})$ with an area of $5 \times 50 \mu \mathrm{m}$ were taken every $5 \mu \mathrm{m}$ per line. The final measurement section (at 25 to $45 \mu \mathrm{m})$ was parallel crossed $(20 \times 50 \mu \mathrm{m})$ in the dentinal tubule area. Distributions and chemical elements in each specimen were examined under the same conditions at $20 \mathrm{kV}$ voltage, $10 \mathrm{~mm}$ working distance and under low pressure $(40 \mathrm{~Pa})$. For each specimen, the average of weight percentages of each element from 0-25 $\mu \mathrm{m}$ and 0-45 $\mu \mathrm{m}$ were calculated. Finally, $\mathrm{Ca} / \mathrm{P}$ stoichiometric ratios and the percentage gain of $\mathrm{Ca} / \mathrm{P}$ ratio after treatment were also valued.

\section{Data Analysis}

Data analysis was performed in RStudio (Version 1.2.1335, RStudio, Inc., Boston, MA, USA). Heatmaps of all data were generated by pheatmap package (Version 1.0.12). Estimation statistics and graphics were performed by DABEST (data analysis with bootstrap-coupled estimation) package (Version 0.2.2) as previously (Ho et al., 2019). About $95 \%$ confidence interval (95\% $\mathrm{CI}$ ) of the mean difference was calculated by performing bootstrap resampling with 5000 resamples (Efron, 1992). Gardner-Altman estimation plot performed two features: Firstly, all data points were presented as a swarmplot and Tufte slopegraph, which orders each measure to display the underlying distribution. Secondly, the effect size was presented as a bootstrap $95 \%$ CI on separate but aligned axes. When the $95 \%$ CI 
bootstrap of difference includes the 0 value of effect size, there is no difference between the two groups (Gardner \& Altman, 1986).

\section{RESULTS}

\section{SEM Revealed the Mineral-Deposition in Dentin Tubular after 28 Days of Tooth Brushing}

Differences were observed between the dentin surfaces obtained before and after treating with two types of toothpaste (Fig. 1C). SEM analysis of exposed dentin surface before treatment of both groups showed typical dentinal tubules and intertubular dentin structure (Fig. 1D). Moreover, remaining dentin layers were characterised by an irregular and rough surface with some smear layer covered on the surface and filled the dentinal tubules (Fig. 1E). Some enlarged dentinal tubules were recorded.

After treatments, the surfaces of demineralised dentin were partially covered by a layer of mineral particles. Mineral particles deposited within the dentinal tubules (Fig. 1F). The partial opening of dentinal tubules with a residual mineral deposit was also demonstrated (Fig. 1G). The well of dentinal tubules was fully occluded by mineral particles (Fig. $1 \mathrm{H}$ ).

\section{EDX and Estimation Statistics Indicated the Alteration of Element Compositions in Primary Dentin Caries Surface}

Heatmap of all weight percentages of $\mathrm{Ca}$, $\mathrm{P}, \mathrm{F}$ and $\mathrm{O}$ from EDX measurement (at $0-5,5-10,10-15,15-20,20-25 \mu \mathrm{m})$ and the average of weight percentages of each element from $0-25 \mu \mathrm{m}$ and $0-45 \mu \mathrm{m}$ were visualised in Fig. 2B. In general, oxygen took the highest percentage in all measurements, followed by calcium, phosphorus respectively while fluoride was lowest.
Different groups being compared included observations from the same specimen (at two time-points, before and after brushing), we used a slopegraph to depict each pair of repeated observations (Fig. 3). The lines in these plots were able to illustrate the presence of any trend between the two timepoints. The calcium weight percentages of 1100 ppm $\mathrm{F}$ toothpaste group were strongly decreased after 28 days in all sections from 0-45 $\mu \mathrm{m}$ (Fig. 3A). In reverse, $950 \mathrm{ppm}$ F-fTCP toothpaste group showed a slightly decreased calcium percentage at the outer layers of the specimens $(0-20 \mu \mathrm{m})$ while the change in $20-45 \mu \mathrm{m}$ areas was undetermined (Fig. 3A). Phosphorus weight percentages were also in the same manner. Estimation analysis indicated that in $1100 \mathrm{ppm} \mathrm{F}$ toothpaste group, phosphorus percentages reduced after 28 days of brushing at $0-25$ $\mu \mathrm{m}$ sections (Fig. 3B). In $950 \mathrm{ppm}$ F-fTCP toothpaste brushed dentin, phosphorus weight percentages did not shift after treatment (Fig. 3B).

In contrast, fluoride weight percentages were increased at $15-20 \mu \mathrm{m}$ and $20-25 \mu \mathrm{m}$ sections in $1100 \mathrm{ppm} \mathrm{F}$ toothpaste group and at $0-5 \mu \mathrm{m}$ section in $950 \mathrm{ppm}$ F-fTCP toothpaste group after 28 days of brushing (Fig. 3C). Additionally, oxygen percentages shifted at all sectional areas in $1100 \mathrm{ppm}$ $\mathrm{F}$ toothpaste group and at only one area $(10-15 \mu \mathrm{m})$ in $950 \mathrm{ppm}$ F-fTCP toothpaste group (Fig. 3D).

Compared to two types of toothbrush groups, there was no difference in weight percentages of any elements (C, P, F, O) between two groups at two time-points (data not shown). Likewise, $\mathrm{Ca} / \mathrm{P}$ stoichiometric ratios were also not different in each type of toothpaste before and after brushing or between two groups at two time-points (Fig. 4A, 4B). Finally, the percentage gain of $\mathrm{Ca} / \mathrm{P}$ ratio after treatment of two kinds of toothpaste was comparable (Fig. 4C). 

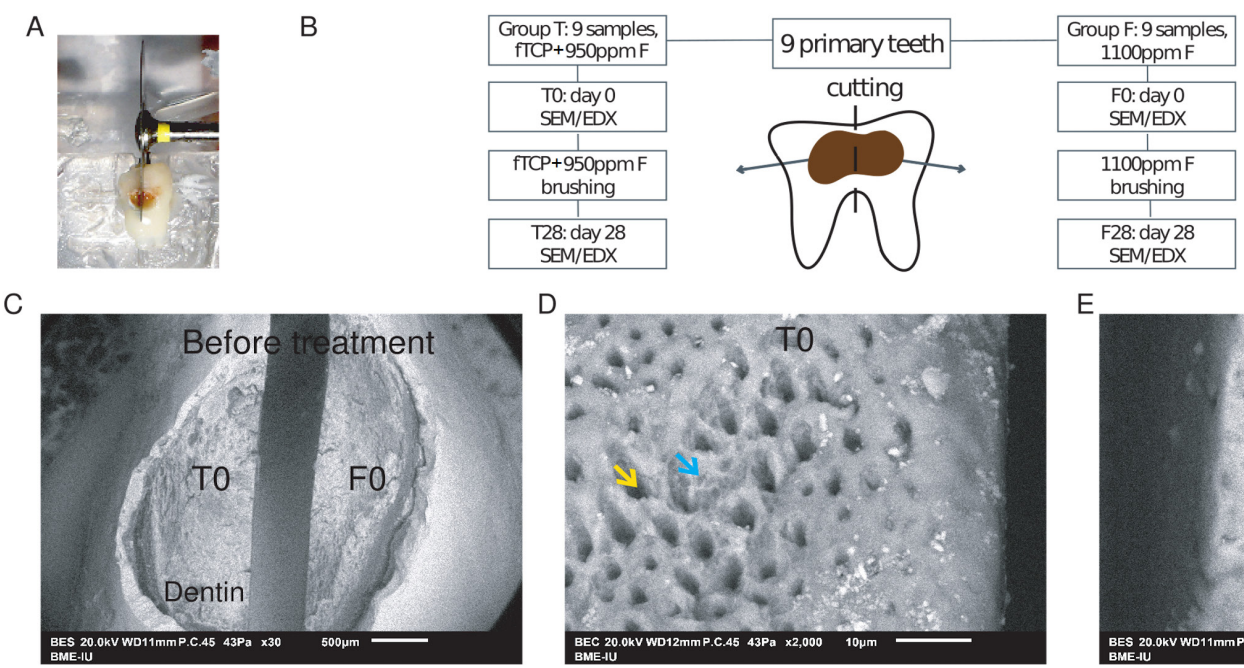

C
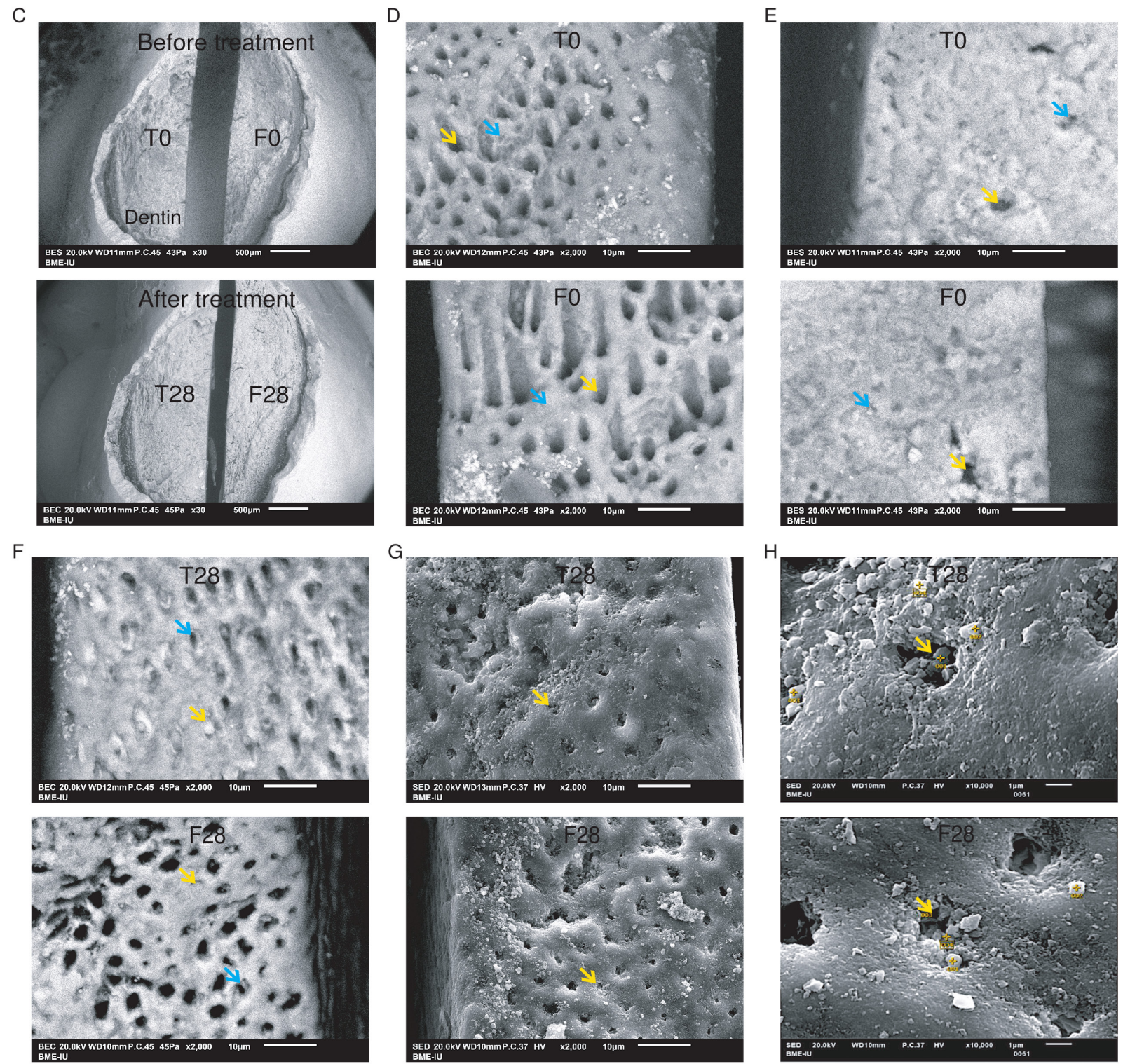

Fig. 1 (A) Caries lesion in buccal surfaces was perpendicularly separated into two blocks. (B) Framework of experimental design. (C) x30 non-coated SEM images of two specimens with the dentin caries lesion from the same tooth before and after treatment. (D) X2000 non-coated SEM images of two groups at day 0 (baseline), blue arrowhead: intertubular dentin, yellow arrowhead: dentinal tubule. (E) X2000 non-coated SEM images of two groups at day 0 (baseline) with an irregular and rough surface with some smear layer covered intertubular dentin and filled the dentinal tubules (blue arrowhead), yellow arrowhead: enlarged dental tubule. (F) x2000 non-coated SEM images of two groups at day 28, yellow arrowhead: mineral-deposited dentinal tubule, blue arrowhead: peritubular dentin. (G) x2000 and (H) x10000 gold-coated SEM images of two groups at day 28, yellow arrowhead: mineral-deposited dentinal tubule. 
A

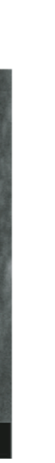

B
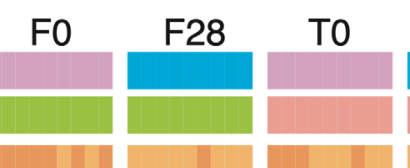
T28
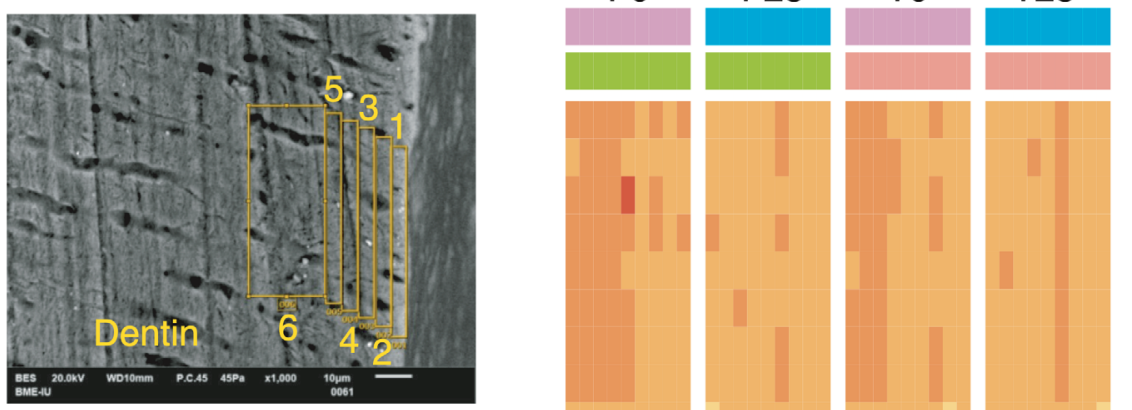

Condition

Treatment

$\% \mathrm{Ca}$ 0_5 $\mu \mathrm{m}$

$\% \mathrm{Ca} 5$ 5_10 $\mu \mathrm{m}$

$\% \mathrm{Ca}^{-10} 15 \mu \mathrm{m}$

$\% \mathrm{Ca}$-15_20 $\mu \mathrm{m}$

$\%$ Ca_20_25 $\mu \mathrm{m}$

$\%$ Ca_25_45 $\mu \mathrm{m}$

$\% \mathrm{Ca} 0 \_25 \mu \mathrm{m}$

$\% \mathrm{Ca}-0 \_45 \mu \mathrm{m}$

$\% \mathrm{P} \_0 \_\overline{5} \mathrm{~m}$

$\%{ }^{2} 510 \mu \mathrm{m}$

$\% \mathrm{P}-10 \_15 \mu \mathrm{m}$

$\% \mathrm{P}^{-15}$ - $20 \mu \mathrm{m}$

$\% \mathrm{P} \_20 \_25 \mu \mathrm{m}$

$\% \mathrm{P} \_25 \_45 \mu \mathrm{m}$

$\% \mathrm{P}_{-0}-25 \mu \mathrm{m}$

$\% \mathrm{P} \_0 \_45 \mu \mathrm{m}$

$\% \mathrm{~F}_{-} 0 \_5 \mu \mathrm{m}$

$\% \mathrm{~F}^{2} 5$-10 $\mu \mathrm{m}$
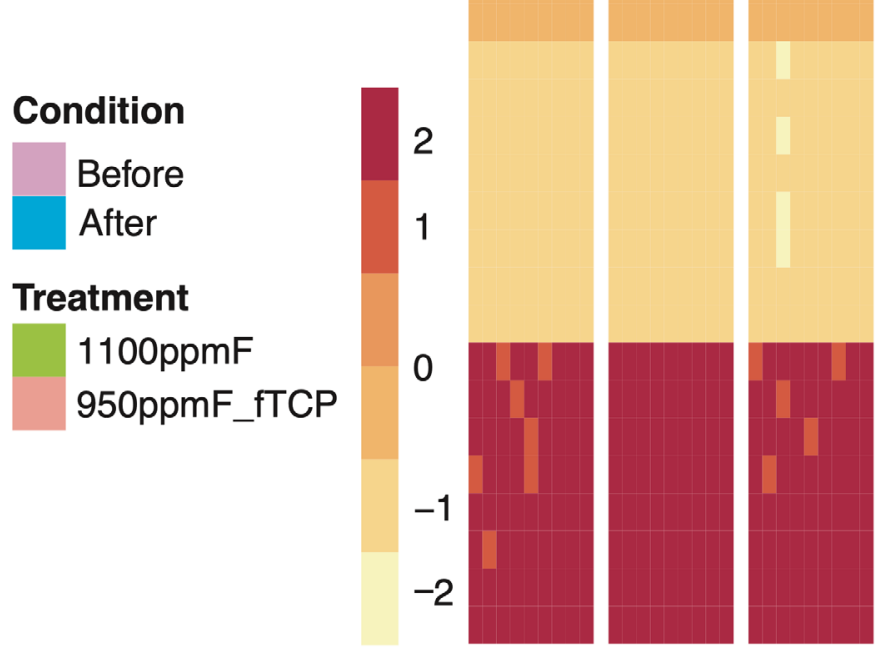

$\% F_{-10}-15 \mu \mathrm{m}$

$\% F_{-15}^{-} 20 \mu \mathrm{m}$

$\% F^{-} 20-25 \mu \mathrm{m}$

$\% \mathrm{~F} \_25 \_45 \mu \mathrm{m}$

$\% \mathrm{~F}_{-} 0 \_25 \mu \mathrm{m}$

$\% \mathrm{~F}_{-}+45 \mu \mathrm{m}$

$\% 0 \_0 \_5 \mu \mathrm{m}$

$\% 0 \_5 \_10 \mu \mathrm{m}$

$\% \mathrm{O}_{-10} 15 \mu \mathrm{m}$

$\% \mathrm{O}_{-15}$ - $20 \mu \mathrm{m}$

$\% 0 \_2025 \mu \mathrm{m}$

$\% O \_25 \_45 \mu \mathrm{m}$

$\% \mathrm{O}-\overline{25} \mu \mathrm{m}$

$\% 0 \_0 \_45 \mu \mathrm{m}$

Fig. 2 (A) EDX measurement areas (1, 2, 3, 4, 5, 6: 0-5, 5-10, 10-15, 15-20, 20-25, 25-45 $4 \mathrm{~m}$, respectively). (B) Heatmap of all weight percentages of Ca, P, F and O from EDX measurement (at 0-5, 5-10, 10-15, 15-20,

20-25 $\mu \mathrm{m})$ and the average of weight percentages of each element from 0-25 $\mu \mathrm{m}$ and 0-45 $\mu \mathrm{m}$.

Data were scaled from actual values to scaled values ( -2 to 2 ) for heatmap visualisation.

\section{DISCUSSION}

Within the scope of this study, we investigated the effects of fluoridated $(\mathrm{NaF}$, $1100 \mathrm{ppm} \mathrm{F}$ ) and $\mathrm{fTCP} /$ fluoride-containing toothpaste $(950 \mathrm{ppm} \mathrm{F})$ on primary dentin caries surface by using EDX and SEM, and applied estimation statistics for the comparison analysis. The study was designed to mimic the real situation where the primary teeth were brushed with different types of toothpaste to remineralise the dentin caries. Dentin samples were low conductivity materials and re-measured after 28 days. In our study model, we used biological sample measurement setting (low vacuum, $20 \mathrm{Kv}$ ) of SEM-EDX spectroscopy instead of high vacuum setting for uncoated dentin samples to avoid burning sample. About $20 \mathrm{kV}$ voltage was also used effectively to measure elements with low atomic number such as fluoride (with nine protons) by increasing the detection capacity (Vicente et al., 2017a; Vicente et al., 2017b; Scimeca et al., 2018). Moreover, the rehydration of human dentin sample could reverse the mechanical property changes due to dehydration process (Jameson et al., 1993; Nalla et al., 2005; 

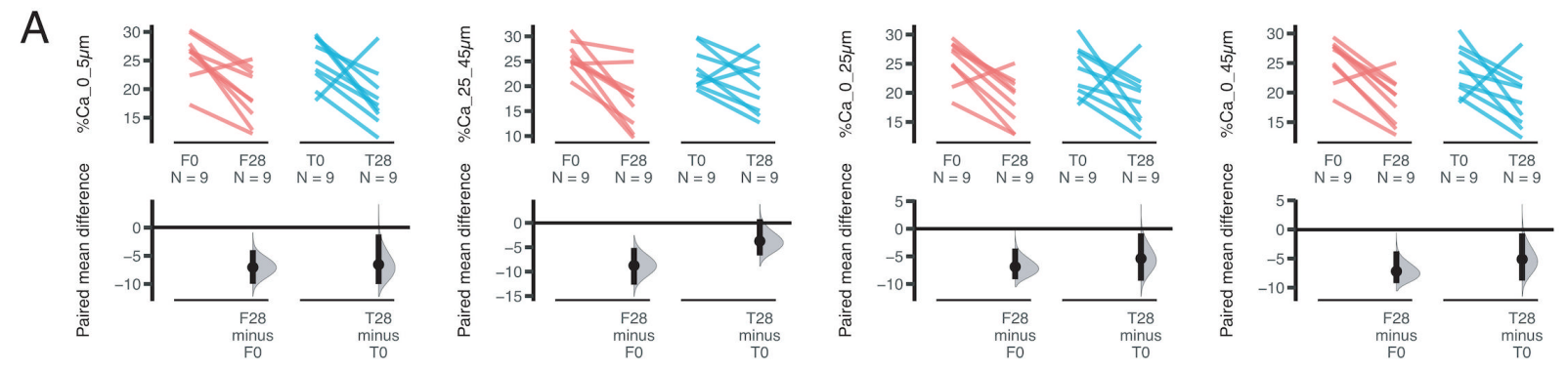

B
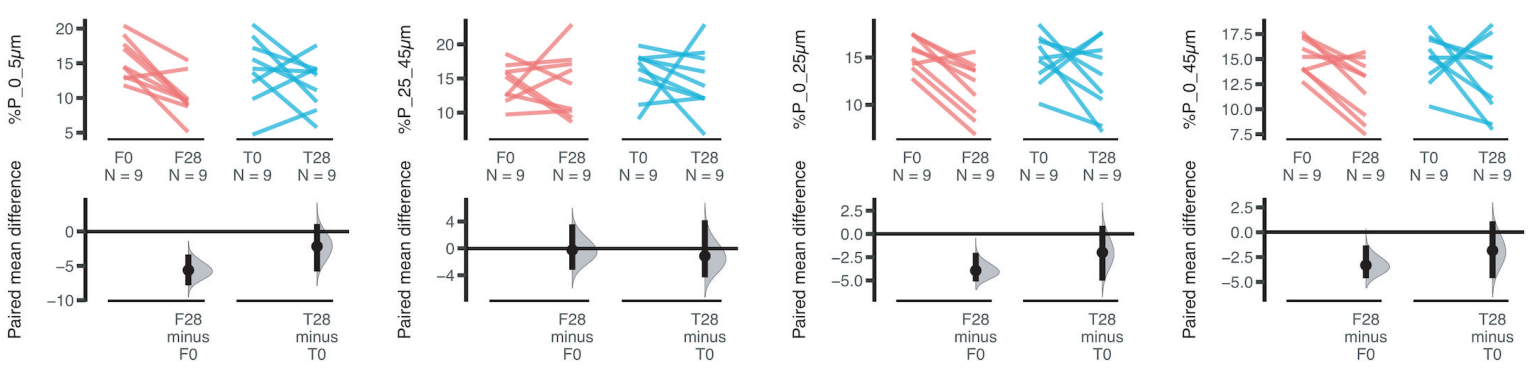

C
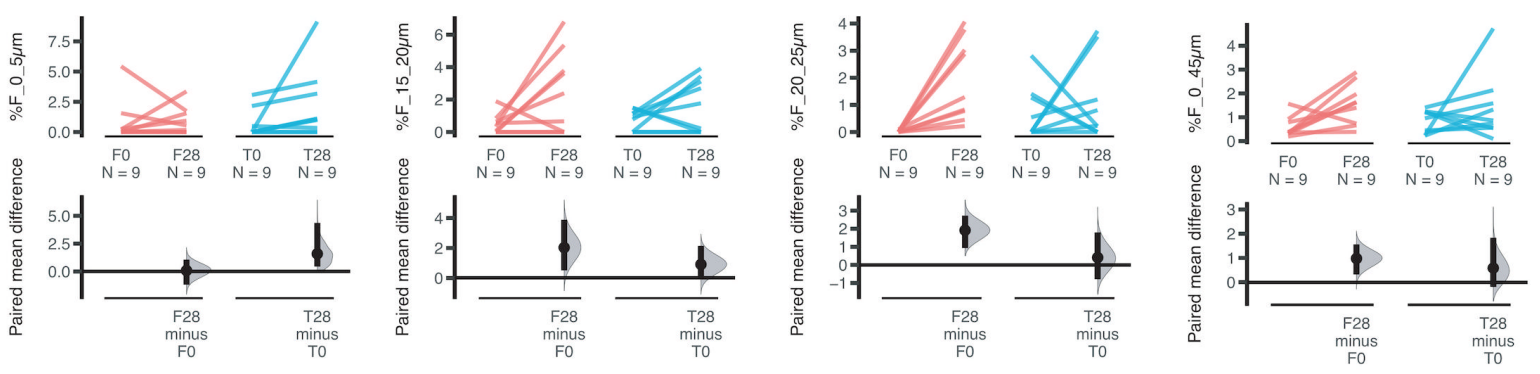

D
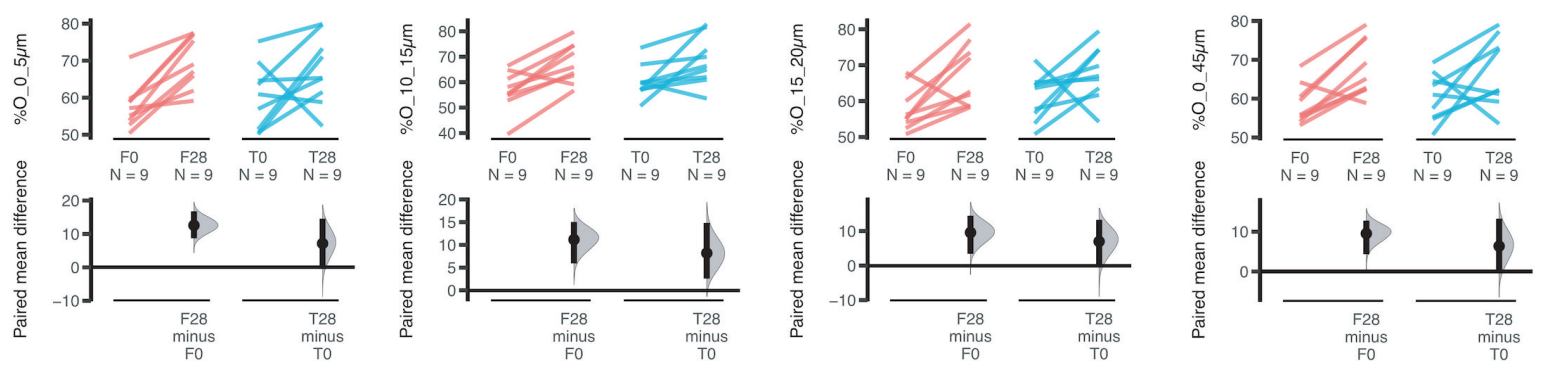

Treatment

- 1100ppmF

- 950ppmF_fTCP

Fig. 3 Estimation comparison of two paired groups (at two time-points, before and after brushing) of each type of toothpaste groups. The weight percentages of (A) calcium (Ca), (B) phosphorus (P), (C) fluoride (F) and (D) oxygen (O) at 0-5, 5-10, 10-15, 15-20, 20-25 $\mu \mathrm{m}$ and the average of weight percentages of each element from 0-25 $\mu \mathrm{m}$ and 0-45 $\mu \mathrm{m}$ were illustrated. Some sections which were not different were not shown. 
A
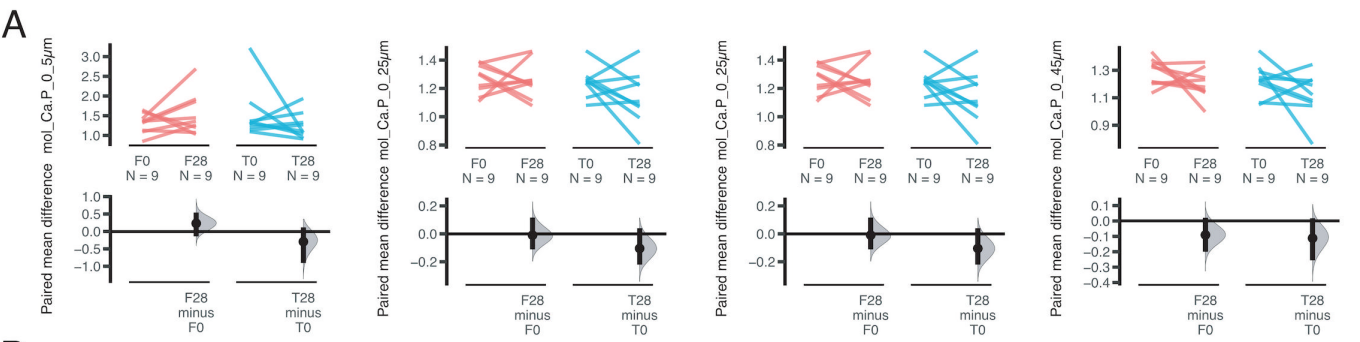

Treatment

- 1100ppmF

- 950ppmF_fTCP

B
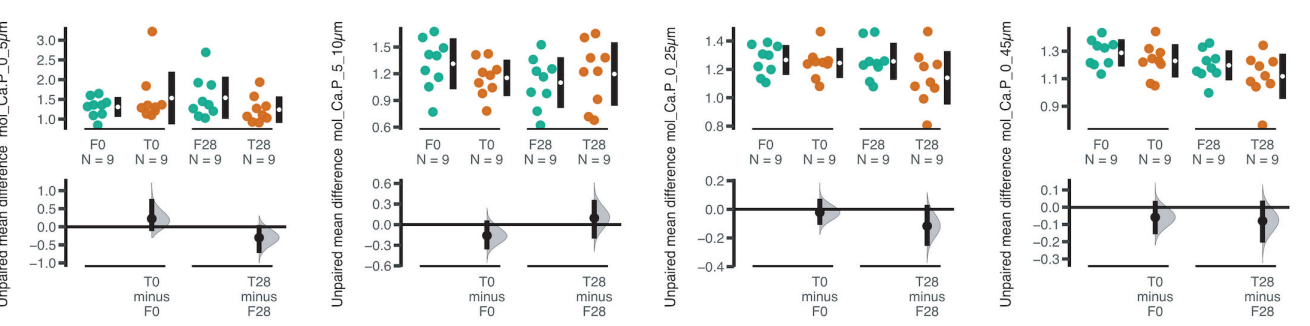

Treatment

1100ppmF

- 950ppmF_fTCP

C
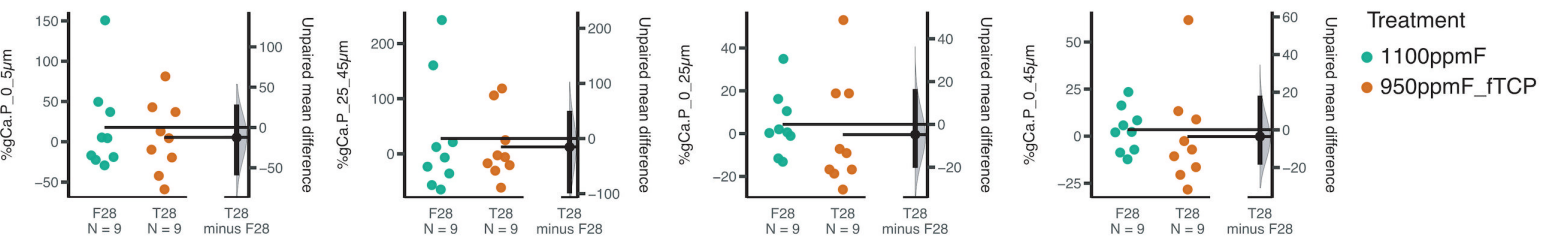

Fig. 4 (A) Estimation comparison of two paired groups (at two time-points, before and after brushing) of each type of toothpaste groups on $\mathrm{Ca} / \mathrm{P}$ stoichiometric ratios. (B) Estimation comparison of two toothpaste groups of each time-points (day 0 and day 28) on $\mathrm{Ca} / \mathrm{P}$ stoichiometric ratios. (C) Estimation comparison of two toothpaste groups on percentage gain of $\mathrm{Ca} / \mathrm{P}$ ratio after 28 days. Some sections which were not different

were not shown.

Nalla et al., 2006). In our study, we used artificial saliva to rehydrate dentin specimens in order to limit any harm during the sample preparing.

SEM is one of the most sensitive, qualitative techniques to evaluate the remineralisation of the dental caries lesions in vitro as reported in previous studies (RodríguezVilchis et al., 2011). Our SEM analysis indicates that both types of the toothpaste moderated the decayed dentin surface in primary teeth which were demonstrated as seen by the formation and deposition of mineral particles within the porous defects. The proposed mechanism could be fTCP fluoride toothpaste providing mineral ions to repair demineralised fluorapatite crystals in decay dentin rather than new crystal formation. However, no difference in the surface morphology was observed between two experimental groups. Noticeably, the deposited mineral crystals were not well oriented and different in nanosized particles in comparison to apatitic crystals of tooth enamel in morphology which suggested that the remineralisation layers were may not uniform HA crystals layer. Although it was not the same as the natural enamel crystals in structure, to some extent, the regenerated tissue was quite similar to the enamel when considering the similar composition and structure to the enamel and the similar protective functions to the dentin (Alhamed et al., 2020; Vinod et al., 2020).

Using a different approach from ordinary statistics methods, we calculated the $95 \%$ CI of the mean difference by performing bootstrap resampling. The bias-corrected and accelerated bootstrap is a simple but powerful technique that creates multiple resamples with replacement from a single set of observations and computes the effect size of interest on each of these resamples. There are two important benefits when 
using bootstrap: There is no need to assume that the observations, or the underlying populations, are normally distributed. Moreover, it is easy for the construction of the $95 \%$ CI from the resampling distribution (Ho et al., 2019). EDX analysis showed that the calcium weight percentages of $1100 \mathrm{ppm}$ $\mathrm{F}$ toothpaste group were clearly decreased in all sections. In reverse, $950 \mathrm{ppm}$ F-fTCP toothpaste group showed a decreased calcium percentage at the outer layers of the specimens. Phosphorus weight percentages were also in the same manner while it did not shift after treatment. Moreover, the extended increase of oxygen and fluoride percentage may affect the percentage of other elements especially the $\mathrm{Ca} / \mathrm{P}$ ratio and increasing $\mathrm{Ca} / \mathrm{P}$ ratio (from average 1.4 to 1.8 at dentin) indicated the remineralization (Rythén et al., 2010). In the fTCP group, we used $950 \mathrm{ppm}$ sodium fluoride toothpaste containing fTCP, which, according to the manufacturer, is an innovative calcium-based additive that can help to remineralize enamel (Karlinsey et al., 2009). We expected that the fTCP toothpaste comprising $950 \mathrm{ppm} \mathrm{F}$ showed a superior effect including the increase of $\mathrm{Ca} / \mathrm{P}$ ratio. However, the outcome of treatment with fTCP and $1100 \mathrm{ppm} \mathrm{F}$ toothpaste was similar that may be explained by the short treatment time (28 days in artificial saliva extra-oral environment). As $\mathrm{Ca} / \mathrm{P}$ ratio is one of dental tissue mineralisation indicators, our results contribute to the fact that different values for the $\mathrm{Ca} / \mathrm{P}$ ratio in enamel have been found in several studies (Lakomaa \& Rytömaa, 1977; Sasaki et al., 1987; Rythén et al., 2010; Paganelli et al., 2015). Our study showed that fluoride toothpaste increased fluoride content of the primary dentin caries surface. However, within the short time of our experiments, there was no clear remineralisation enhancement evidence as the formation of fluorapatite in the mineral dental tissue is a long timeconsuming process. In fact, it requires the presence of fluoride for a long period (Rølla \& Saxegaard, 1990; Vicente et al., 2017a). The diversity and complexity of primary dentin caries may help to explain the difficulty and complexity of remineralization by different types of toothpaste in daily practice (Chen et al., 2021). Clinically, in the limit of this study, we propose that using $950 \mathrm{ppm}$ fluoride fTCP toothpaste may moderate primary dentin caries and increase fluoride content. Further studies need to be performed with longer experimental duration to investigate the effects of F-fTCP toothpaste.

\section{CONCLUSION}

There was an alteration of dentin caries surface after treatment with two kinds of toothpaste for 28 days in vitro. The combination of fTCP and $950 \mathrm{ppm}$ fluoride in toothpaste showed equivalent effectiveness to the $1100 \mathrm{ppm}$ fluoride toothpaste in primary dentin caries.

\section{ACKNOWLEDGEMENTS}

We thank Dr. Nguyen Thi Hiep from Tissue Engineering and Regenerative Medicine Laboratory, Department of Biomedical Engineering, International University, Vietnam National University- Ho Chi Minh City (VNU-HCM), Ho Chi Minh City 700000, Vietnam for his support in this study.

\section{REFERENCES}

Alhamed M, Almalki F, Alselami A, Alotaibi T, Elkwatehy W (2020). Effect of different remineralizing agents on the initial carious lesions - A comparative study. Saudi Dent F, 32(8): 390-395. https://doi.org/10.1016/j. sdentj.2019.11.001

Amrhein V, Greenland S, McShane B (2019). Scientists rise up against statistical significance. Nature, 567: 305-307. https:// doi.org/10.1038/d41586-019-00857-9 
Chen KJ, Gao SS, Duangthip D, Lo ECM, Chu CH (2021). Randomized Clinical Trial on Sodium Fluoride with Tricalcium Phosphate. f Dent Res, 100(1): 66-73. https://doi.org/10.1177/0022034520952031

de Azevedo CS, Garbui BU, e Silva CM, Simionato MRL, de Freitas AZ, Matos AB (2014). Obtaining artificially caries-affected dentin for in vitro studies. $\mathcal{F}$ Contemp Dent Pract, 15(1): 12-19. https://doi. org/10.5005/jp-journals-10024-1480

Efron B (1992). Bootstrap methods: Another look at the Jackknife. In: Kotz S, Johnson NL (eds.), Breakthroughs in Statistics. Springer Series in Statistics (Perspectives in Statistics). New York: Springer. pp. 569593. https://doi.org/10.1007/978-1-46124380-9_41

Gardner MJ, Altman DG (1986). Confidence intervals rather than $P$ values: Estimation rather than hypothesis testing. $\mathrm{Br} \mathrm{Med}$ f (Clin Res Ed), 292(6522): 746-750. https://doi.org/10.1136/bmj.292.6522.746

Ho J, Tumkaya T, Aryal S, Choi H, ClaridgeChang A (2019). Moving beyond $P$ values: Data analysis with estimation graphics. Nat Methods, 16(7): 565-566. https://doi.org/ 10.1038/s41592-019-0470-3

Jameson MW, Hood JA, Tidmarsh BG (1993). The effects of dehydration and rehydration on some mechanical properties of human dentine. If Biomech, 26(9): 1055-1065. https://doi.org/10.1016/s0021-9290(05) 80005-3

Kamath P, Nayak R, Kamath SU, Pai D (2017). A comparative evaluation of the remineralization potential of three commercially available remineralizing agents on white spot lesions in primary teeth: An in vitro study. $\mathcal{F}$ Indian Soc Pedod Prev Dent, 35(3): 229-237. https://doi.org/ 10.4103/JISPPD.JISPPD_242_16
Karlinsey RL, Mackey AC, Stookey GK, Pfarrer AM (2009). In vitro assessments of experimental $\mathrm{NaF}$ dentifrices containing a prospective calcium phosphate technology. Am F Dent, 22(3): 180-184.

Karlinsey RL, Pfarrer AM (2012). Fluoride plus functionalized $\beta$-TCP: A promising combination for robust remineralization. Adv Dent Res, 24(2): 48-52. https://doi. org/10.1177/0022034512449463

Khanh LN, Ivey SL, Sokal-Gutierrez K, Barkan H, Ngo KM, Hoang HT et al. (2015). Early childhood caries, mouth pain, and nutritional threats in Vietnam. $A m$ f Public Health, 105(12): 2510-2517. https://doi.org/10.2105/AJPH.2015.302798

Lakomaa EL, Rytömaa I (1977). Mineral composition of enamel and dentin of primary and permanent teeth in Finland. Scand J Dent Res, 85(2): 89-95. https://doi. org/10.1111/j.1600-0722.1977.tb00537.x

Nalla RK, Balooch M, Ager JW 3rd, Kruzic JJ, Kinney JH, Ritchie RO (2005). Effects of polar solvents on the fracture resistance of dentin: Role of water hydration. Acta Biomater, 1(1): 31-43. https://doi.org/10 $.1016 /$ j.actbio.2004.08.002

Nalla RK, Kinney JH, Tomsia AP, Ritchie RO (2006). Role of alcohol in the fracture resistance of teeth. F Dent Res, 85(11): 1022-1026. https://doi.org/10.1177/154405 910608501109

Oliveira P, Fonseca A, Silva EM, Coutinho T, Tostes MA (2016). Remineralizing potential of CPP-ACP creams with and without fluoride in artificial enamel lesions. Aust Dent F, 61(1): 45-52. https://doi. org/10.1111/adj.12305

Paganelli C, Zanarini M, Pazzi E, Marchionni S, Visconti L, Alessandri Bonetti G (2015). Interproximal enamel reduction: An in vivo study. Scanning, 37(1): 73-81. https:/doi. org/10.1002/sca.21181 
Rodríguez-Vilchis LE, Contreras-Bulnes R, OleaMejìa OF, Sánchez-Flores I, CentenoPedraza C (2011). Morphological and structural changes on human dental enamel after Er:YAG laser irradiation: AFM, SEM, and EDS evaluation. Photomed Laser Surg, 29(7): 493-500. https://doi.org/10.1089/pho .2010 .2925

Rølla G, Saxegaard E (1990). Critical evaluation of the composition and use of topical fluorides, with emphasis on the role of calcium fluoride in caries inhibition. $\mathcal{F}$ Dent Res, 69 Spec No: 780-785. https://doi. org/10.1177/00220345900690S150

Rythén M, Sabel N, Dietz W, Robertson A, Norén JG (2010). Chemical aspects on dental hard tissues in primary teeth from preterm infants. Eur $\mathcal{F}$ Oral Sci, 118(4): 389-395. https://doi.org/10.1111/j.16000722.2010.00755.x

Sasaki T, Debari K, Garant PR (1987). Ameloblast modulation and changes in the $\mathrm{Ca}, \mathrm{P}$, and $\mathrm{S}$ content of developing enamel matrix as revealed by SEM-EDX. F Dent Res, 66(3): 778-783. https://doi.org/10.117 $7 / 00220345870660031501$

Scimeca M, Bischetti S, Lamsira HK, Bonfiglio R, Bonanno E (2018). Energy Dispersive X-ray (EDX) microanalysis: A powerful tool in biomedical research and diagnosis. Eur $\mathcal{F}$ Histochem, 62(1): 2841. https://doi. org/10.4081/ejh.2018.2841

Sumikawa DA, Marshall GW, Gee L, Marshall SJ (1999). Microstructure of primary tooth dentin. Pediatr Dent, 21(7): 439-444. ten Cate JM (2013). Contemporary perspective on the use of fluoride products in caries prevention. Br Dent F, 214(4): 161-167. https://doi.org/10.1038/sj.bdj.2013.162

Vicente A, Ortiz Ruiz AJ, González Paz BM, García López J, Bravo-González LA (2017a). Efficacy of fluoride varnishes for preventing enamel demineralization after interproximal enamel reduction. Qualitative and quantitative evaluation. PLoS One, 12(4): e0176389. https://doi.org/10.1371/ journal.pone.0176389

Vicente A, Ortiz Ruiz AJ, López MG, Beneyto YM, Bravo-González LA (2017b). Enamel resistance to demineralization after bracket debonding using fluoride varnish. Sci Rep, 7(1): 15183. https://doi.org/10.1038/ s41598-017-15600-5

Vinod D, Gopalakrishnan A, Subramani SM, Balachandran M, Manoharan V, Joy A (2020). A comparative evaluation of remineralizing potential of three commercially available remineralizing agents: An in vitro study. Int $\mathcal{F}$ Clin Pediatr Dent, 13(1): 61-65. https://doi.org/10.5005/ jp-journals-10005-1715

Wasserstein RL, Schirm AL, Lazar NA (2019). Moving to a world beyond " $p<0.05$ ". Am Stat, 73(Sup1): 1-19. https://doi.org/10 $.1080 / 00031305.2019 .1583913$

Yamaguchi K, Miyazaki M, Takamizawa T, Inage H, Moore BK (2006). Effect of CPP-ACP paste on mechanical properties of bovine enamel as determined by an ultrasonic device. F Dent, 34(3): 230-236. https://doi.org/10.1016/j.jdent.2005.06.005 